\title{
Linear Induction Accelerator Approach for Advanced Radiography
}

\author{
George J. Caporaso
}

This paper was prepared for submittal to the

1997 Particle Accelerator Conference

Vancouver, B. C. Canada

May 12-16, 1997

May 1997

This is a preprint of a paper intended for publication in a journal or proceedings. Since changes may be made before publication, this preprint is made available with the understanding that it will not be cited or reproduced without the permission of the author. 


\section{DISCLAIMER}

This document was prepared as an account of work sponsored by an agency of the United States Government. Neither the United States Government nor the University of California nor any of their employees, makes any warranty, express or implied, or assumes any legal liability or responsibility for the accuracy, completeness, or usefulness of any information, apparatus, product, or process

disclosed, or represents that its use would not infringe privately owned rights. Reference herein to any specific commercial product, process, or service by trade name, trademark, manufacturer, or otherwise, does not necessarily constitute or imply its endorsement, recommendation, or favoring by the United States Government or the University of California. The views and opinions of authors expressed herein do not necessarily state or reflect those of the United States Government or the University of California, and shall not be used for advertising or product endorsement purposes. 


\title{
LINEAR INDUCTION ACCELERATOR APPROACH FOR ADVANCED RADIOGRAPHY
}

\author{
George J. Caporaso, Lawrence Livermore National Laboratory, Livermore, California 94550, USA
}

\section{Abstract}

Recent advances in induction accelerator technology make it possible to envision a single accelerator that can serve as an intense, precision multiple pulse $\mathrm{x}$-ray source for advanced radiography. Through the use of solid-state modulator technology repetition rates on the order of 1 $\mathrm{MHz}$ can be achieved with beam pulse lengths ranging from $200 \mathrm{~ns}$ to $2 \mu \mathrm{secs}$. By using fast kickers, these pulses may be sectioned into pieces which are directed to different beamlines so as to interrogate the object under study from multiple lines of sight. The ultimate aim is to do a time dependent tomographic reconstruction of a dynamic object. The technology to accomplish these objectives along with a brief discussion of the experimental plans to verify it will be presented.

\section{INTRODUCTION}

Induction linacs, because of their kiloampere current capability are used as intense flash x-ray sources. A novel approach, illustrated in Fig. 1 is to generate a train of several pulses in one accelerator which can be sectioned into pieces by kickers and directed down different beamlines. These pieces will go through kickers and several large angle bends in order to arrive at the x-ray targets simultaneously.

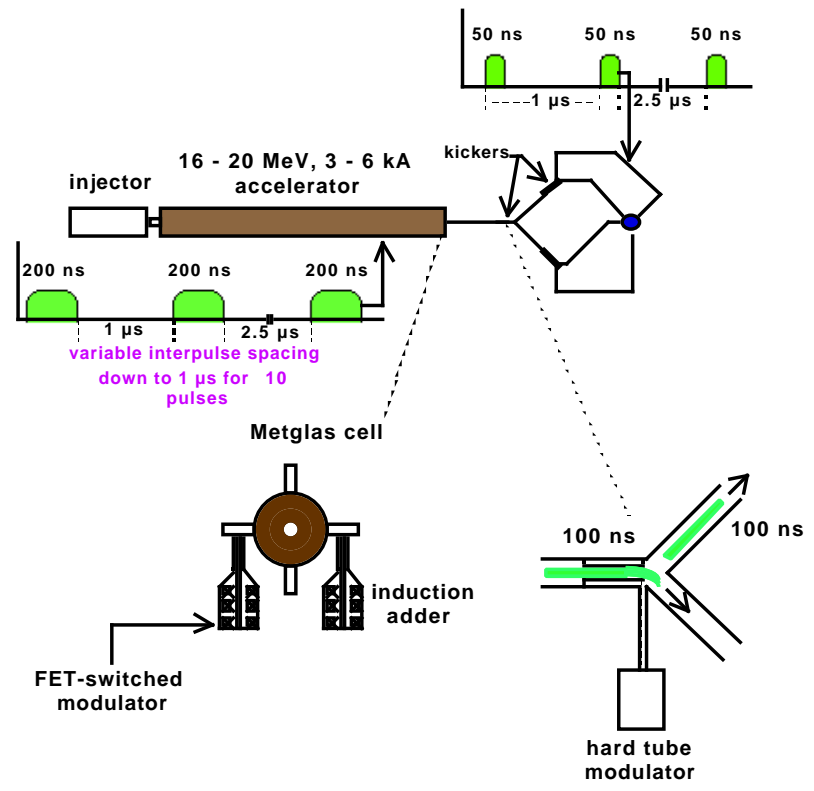

Fig. 1 Schematic of induction linac advanced radiography concept
The electron beam is focused to a small spot, typically of order $1 \mathrm{~mm}$, onto a Bremsstrahlung target. The x-ray brightness depends on the electron beam's final spot size and divergence angle, and hence on its emittance. The performance of a radiographic machine using a single accelerator as a driver depends on whether beam quality can be preserved throughout these beam manipulations. The effects of space charge forces on the emittance growth in these bends has been calculated and appears to be small [1].

\section{ARM SOLID-STATE MODULATOR}

The ARM (Advanced Radiography Machine) solid-state modulator concept is shown in Fig. 2. The voltage to be applied to the load (ultimately an accelerator cell) is that of the precharged capacitor. A suitable switch alternately connects and disconnects the capacitor from the load. Another branch of the circuit acts independently to reset the magnetic core material of the induction cell to prepare it for another voltage pulse.

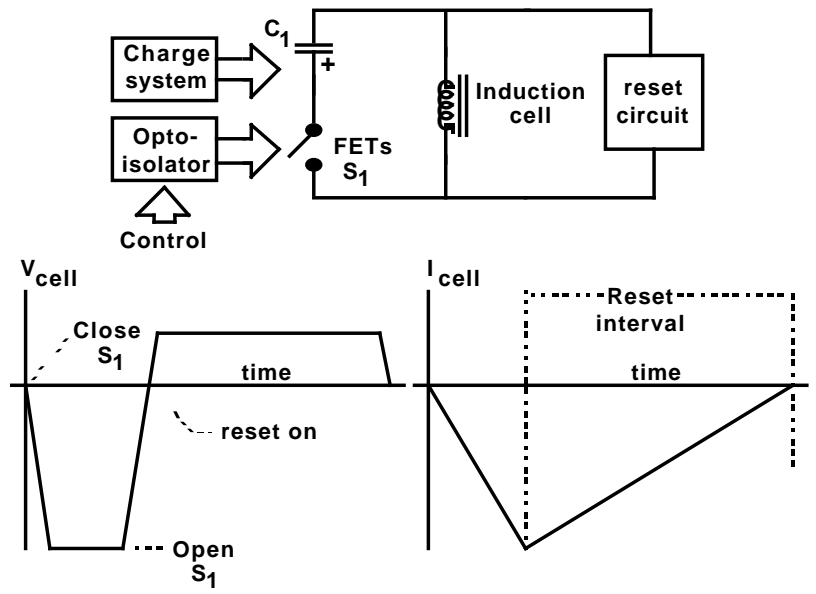

Fig. 2 Schematic of solid-state modulator concept

In this case the switch is a series-parallel array of FET's (Field Effect Transistors). These devices are inherently fast but have limited voltage and current capacity. Thus, they must be arranged in parallel to handle large currents and in series to handle high voltages. Fig. 3 shows a switch circuit board with 12 FET's capable of handling $1.2 \mathrm{kA}$ at approximately $1 \mathrm{kV}$. Many of these circuit boards along with reset boards and the primary energy storage capacitors are arranged around a Metglas core to form the ARM-II modulator shown in Fig. 4. This modulator has 
successfully operated at its design parameters of $15 \mathrm{kV}$ (open circuit voltage) and up to $6.7 \mathrm{kA}$ (where it is internally current limited) for pulses between 200ns up to $2 \mu$ secs in duration.

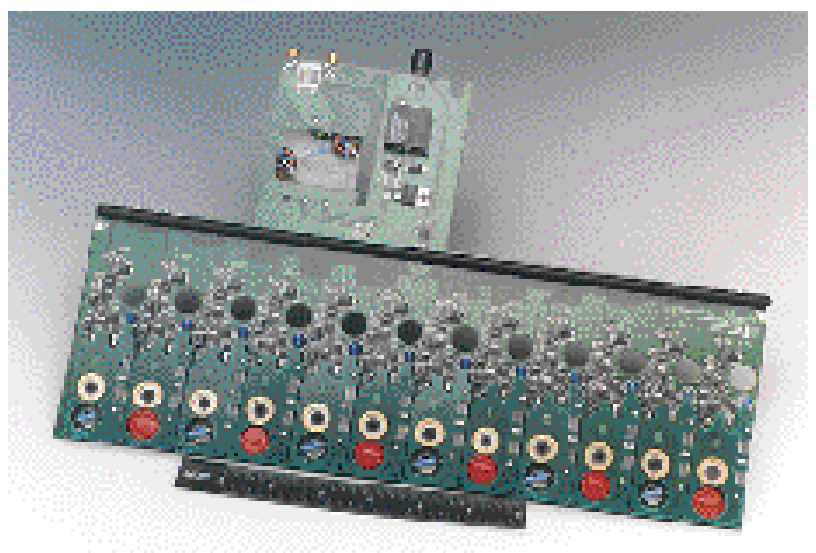

Fig. 3 ARM-II switchboard containing 12 FET's

The modulator has been fired at full power into a short circuit and operated without damage. Without reset the modulator can produce a string of $200 \mathrm{~ns}$ pulses at a repetition rate of $2 \mathrm{MHz}$.

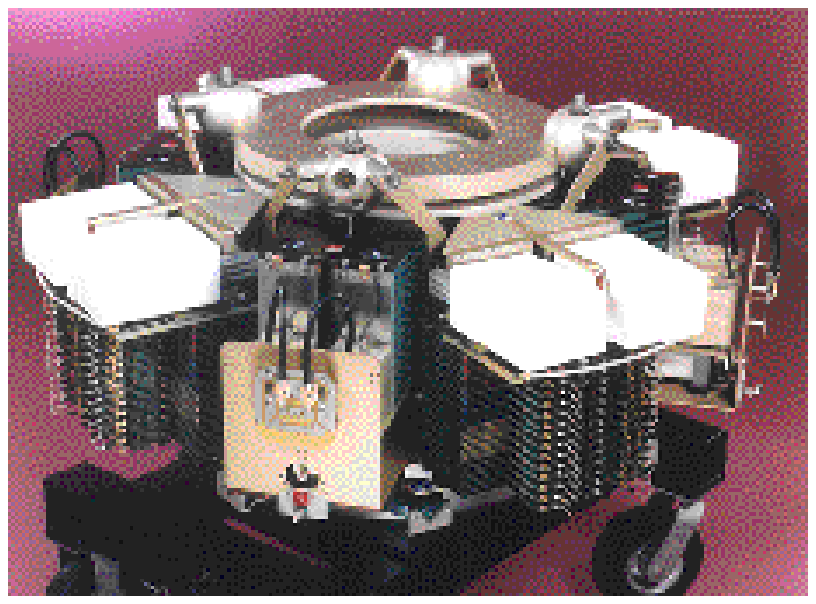

Fig. 4 Assembled ARM-II modulator

Fig. 5 shows a pulse sequence that might be used for advanced radiography. It consists of $11 \mu \mathrm{sec}$ pulse followed by a string of 3,200 ns pulses followed by a 2 $\mathrm{MHz}$ burst of 5, $200 \mathrm{~ns}$ pulses.

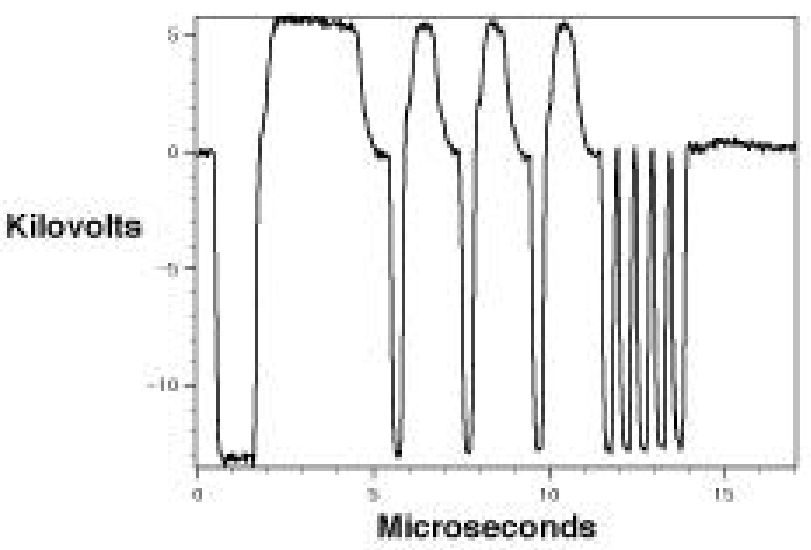

Fig. 5 A candidate accelerating pulse format for advanced radiography

\section{FAST KICKER SYSTEM}

The kicker system concept is illustrated in Fig. $6 . \quad$ It consists of stripline electrodes and is very similar to a stripline BPM. By driving the downstream end of two of the electrodes with a fast pulser the beam can be deflected in one plane. A D.C. bias dipole wound over the kicker is used to steer the beam to one of the two desired output positions in the absence of a pulse. When the pulser is activated, the voltage and current on the strips overcome the bias field and switch the beam to the other output position. The kicker is followed by a drift space in which the effects of the kicker are amplified. A separation of several centimeters in the two output positions is readily achieved but a large angular separation between the two beams is not. The beams are then passed through a D.C. septum magnet which changes the angles of the two output beams fairly abruptly so that there will be room to insert additional focusing lenses.

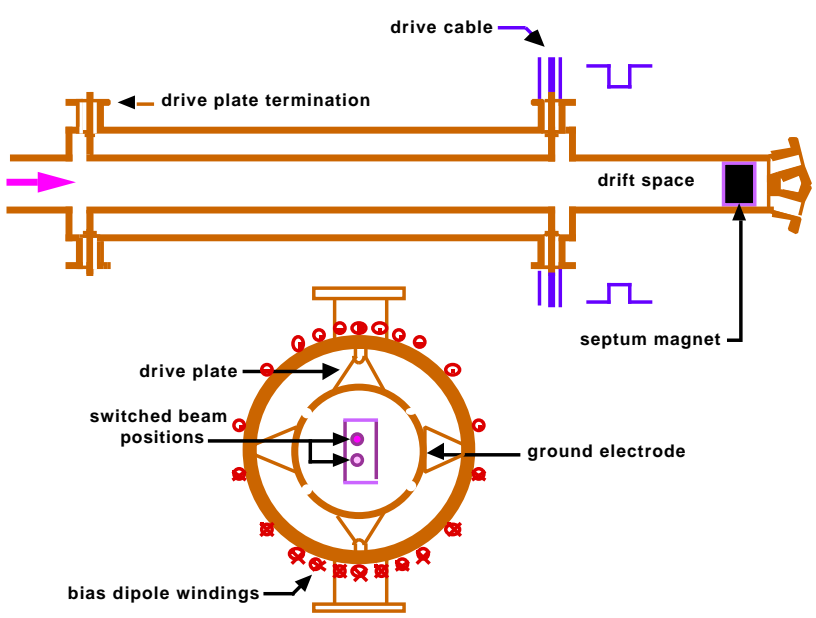

Fig. 6 Fast kicker system

The passage of a high current beam through the kicker will induce currents and voltages in the structure which will act to amplify the effects of the externally applied 
deflecting signals $[2,3]$. These effects can be made small in a properly designed system and can be compensated by using a pulser with an adjustable output waveform. A very fast pulse risetime is desired in order to minimize the amount of beam that is lost on the septum pipe. The pulses are provided by a hard tube modulator with a bandwidth on the order of $40 \mathrm{MHz}$. This system is essentially an amplifier which can provide a pulse that is custom tailored to accommodate the effects of any beam induced voltage in the system. Because kiloampere level beam currents will pass through the kicker relatively large voltages will be generated which will run up the drive cables to the pulser where they will reflect and come back down to the kicker perturbing subsequent sections of the beam. One way to eliminate these reflections is to use a transit time isolated cable system. Unfortunately for the time windows under consideration (10's of $\mu$ secs) the skin effect in conventional conductors makes this impossible without unacceptable high frequency attenuation. The attenuation and dispersion can be greatly reduced by using a superconducting delay line [4].

\section{ETA-II EXPERIMENTS}

In order to test various aspects of kicker performance and to verify the preservation of beam quality through large angle achromatic bends a series of experiments will be performed on the ETA-II induction accelerator [5]. ETA-II produces high quality electron beam pulses of 6.3 $\mathrm{MeV}$ at $2.2 \mathrm{kA}$ with an energy flat top of $\pm 1 \%$ over 40 ns. A series of extensive kicker/septum measurements are planned for the 1997 fiscal year. Beam induced voltages, and their effect on steering, emittance growth and pulser response will all be measured as a function of beam current from roughly $100 \mathrm{~A}$ up to the full current of the machine $(2.2 \mathrm{kA})$. Eventually, the ARM three-stage inductive adder will be used to power a long pulse accelerator cell installed on the ETA-II beamline to provide a complete system test of the solid-state modulator technology with an actual beam load.

\section{CONCLUSIONS}

We have presented a concept for an advanced radiographic system that should be capable of providing multiple lines of sight to an object with a temporal sequence of pulses at a very high repetition rate sufficient to image a dynamic object.

\section{ACKNOWLEDGMENTS}

The author gratefully acknowledges helpful discussions with Hugh Kirbie. The work was performed under the auspices of the U.S. Department of Energy by LLNL under contract W-7405-ENG-48.

\section{REFERENCES}

[1] Yu-Jiuan Chen, "Space-Charge Forces Of A Dc Beam In A Continuous Bend", this conference.

[2] B. Poole, G. Caporaso and W. Ng, "Wake Properties of Stripline Beam Kicker", this conference.

[3] G. Caporaso, $\mathrm{Yu} \mathrm{Ju}$ Chen and B. Poole, "Transmission Line Analysis of Beam Deflection in a BPM Stripline Kicker", this conference.

[4] Yu Ju Chen and G. Caporaso, "A Novel Design for a High Power Superconducting Delay Line", this conference.

[5] J. Weir, et. al., "ETA-II Experiments for Determining Advanced Radiographic Capabilities of Induction Linacs", this conference. 


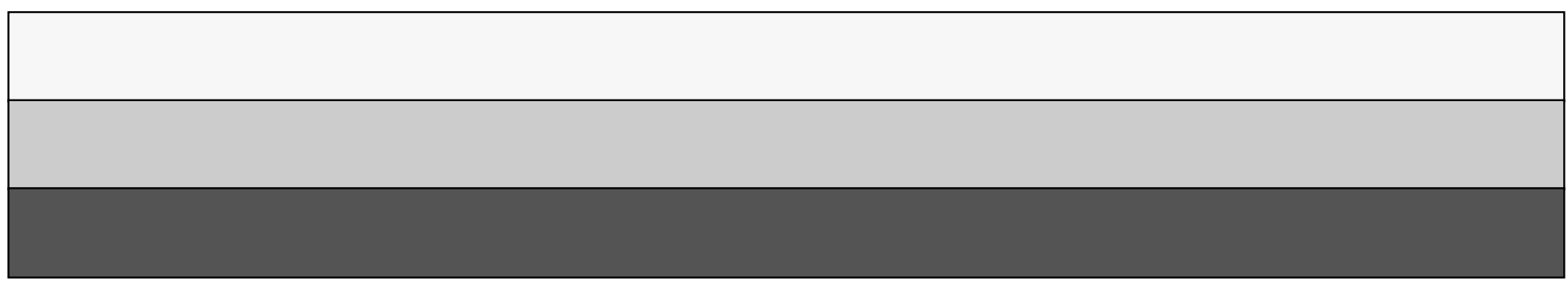

